\title{
Research on optimal allocation strategy of multi-energy storage in regional integrated energy system considering the quantification of low-carbon economic benefits
}

\author{
Kecheng Wu ${ }^{1}$, Quan Chen ${ }^{1}$, Jiajia Huan ${ }^{2 *}$, Xin Huang ${ }^{2}$, Mintong Zhao ${ }^{1}$ and Yijun Wang ${ }^{3}$ \\ ${ }^{1}$ Guangdong Power Grid Co., Guangzhou, China \\ 2 Power Grid Planning and Research Center Guangdong Power Grid Co., Guangzhou, China \\ ${ }^{3}$ China Energy Construction Group Guangdong Electric Power Design and Research Institute Co., Guangzhou, China
}

\begin{abstract}
The dual pressure of energy crisis and environmental pollution has prompted the world's energy sector to change in the direction of clean, efficient, sustainable and pollution-free, and RIES (Regional Integrated Energy System) has emerged. The deployment of energy storage devices in the RIES can deepen the connection of each energy system, release the spatial and temporal constraints of multiple energy sources, and thus improve the energy utilization and economy of the integrated energy system. Based on the infrastructure and model of the RIES, this paper studied the synergistic optimal configuration of electricity storage, power-to-gas (P2G) technology, cooling storage and heating storage in the case of multi-energy complementation operation of combined cooling, heating and power supply (CCHP) unit and other equipment. Firstly, an optimal configuration model of multiple energy storage in the RIES based on the optimal operational economy was proposed. Then, the economics and feasibility of configuring different energy storage combinations in the system were analyzed. Finally, the benefits of energy storage devices in the regional integrated energy system were quantified and analyzed by the economic indicators and low carbon emissions reduction indicators. By employing an industrial district RIES in northern China as the study case, the operation scheduling scheme and energy storage allocation scheme were solved by the optimization model proposed in this paper. The results show that the RIES containing multiple types of energy storage can consume more distributed new energy, improve economic efficiency and reduce carbon emissions. And this model has a good application prospect.
\end{abstract}

\section{Introduction}

Energy Internet is a product of the deep combination of energy industry and Internet thinking, which covers multiple systems such as electricity, gas, cooling, and heating. It is an effective way to promote the revolution of energy production and consump-tion in the world [12]. RIES (Regional integrated energy system) is an important physical carrier of Energy Internet. It can effectively compensate for the defects of previous separate planning and independent operation through the unified planning and collaborative operation of each energy system, and improve the efficiency of energy and utilization of asset. RIES is directly connected to different regional loads by integrating regional energy equipment such as CCHP units, Power to Gas (P2G) systems, heat pumps, and energy storage. Moreover, it provides reliable and economical energy to customers by combining controllable loads such as distributed new energy and electric vehicle clusters in the region.

RIES is one of the important research hotspots at present, which involves many research aspects such as structural design, operation control, power quality, economic operation, simulation analysis, and demonstration projects [3-4]. With the gradual penetration of distributed energy and DC loads, the establishment of deep integration with the existing $\mathrm{AC}$ power system, it can meet the personalized needs of local energy consumption and load demand response to the maximum extent. Energy storage is an important component and key support technology for integrated energy system, with the advantages of smoothing the net load curve, promoting new energy con-sumption, reducing operating costs, etc. It can solve the mismatch between energy production and consumption in time, meet the requirements of social development for the safety and reliability of energy supply. Moreover, it is an important means to improve the energy utilization efficiency and economy of integrated energy system [5].

The economics of electricity storage devices are mainly profitable by "storing elec-tricity when the price is low and generating electricity when the price is high", and they can only be charged and discharged several times a day, so the profitability is small. The paper [6] investigated the compatibility of electricity storage devices in RIES when they participate in different types of auxiliary services of the power system. In addition, it

\footnotetext{
"Corresponding author's e-mail: huanjiajia@gd.csg.cn
} 
analyzed and calculated the benefits of electricity storage devices partici-pating in different types of auxiliary services. Phase change energy storage and sensi-ble thermal energy storage are typical cold/heat storage methods. The paper [7] con-cluded that wind power thermal storage is more promising from the perspective of national economy and coal saving, and thermal storage boilers convert electrical energy into thermal energy, breaking the constraint of "heat-dependent" model. The paper [8] proposed a CCHP-MG multi-timescale optimal dispatching model with ice storage air conditioners as the main component, and studied the impact of different operation modes of ice storage air conditioners on the optimal dispatching of inte-grated energy systems. The P2G technology emerged in recent years as a promising way to solve the new energy consumption problem. The paper [9] established a new electrical hybrid energy storage model of hydrogennatural gas based on $\mathrm{P} 2 \mathrm{G}$ tech-nology and found that the high penetration rate of wind power to the grid not affect the system economy and environmental friendliness. For multi-energy flow energy storage, the paper [10] established a micro energy interconnection system with gas-electricity-thermal integration, and investigated the cost comparison under single, dual and multi-storage modes with the objective of system economics, and found that the economics of hybrid energy storage is optimal.

In the existing energy storage planning, most of the papers tended to consider one kind of energy storage technology or hybrid electric energy storage, without consider-ing the complementary relationship between different energy sources and the role of energy storage in other energy systems. From the perspective of integrated energy system analysis, such planned energy storage was not optimal. In addition, a few researches containing multi-energy storage still mainly considered its economic bene-fits. In the context of the current global policy of energy saving and emission reduc-tion, it was necessary to study the low carbon emission reduction benefits of multi-type energy storage for RIES. In view of these, this paper applied multiple types of energy storage devices for electricity, gas, cooling and heating to the regional integrat-ed energy system. And an integrated energy system model containing wind turbine, photovoltaic, gas turbine, absorption chiller, gas boiler, thermal storage electric boiler, ice storage device, battery device and P2G system was established. Then, considering the timesharing electricity prices mechanism, an optimal allocation strategy for ener-gy storage by balancing the cooling, heating and electricity loads and minimizing the operating economy cost was proposed. The model was solved by $0-1$ mixed integer linear programming software. Finally, the economic benefits and low carbon emission reduction benefits of energy storage for integrated energy system were quantified and analyzed. The feasibility of the regional integrated energy system containing four types of energy storage: electricity, gas, cooling and heating was demonstrated through a practical case.

\section{Main equipment and mathematical models of regional integrated energy system}

The integrated energy system contains four forms of energy: electricity, gas, cooling and heating. And it is characterized by a variety of load types and extensive energy supply equipment. The system energy supply structure expressed based on the bus structure of electricity, gas, cooling and heat is shown in Figure 1. Electricity is coupled to the heating and cooling network through electric boiler and electric chiller, and to the natural gas network through $\mathrm{P} 2 \mathrm{G}$ and gas storage device. The heating supply network can realize energy transmission to the cooling network through absorption chiller equipment. Meanwhile, the gas supply network can provide energy for other network energy production equipment. This integrated energy system sets four types of energy storage devices as options, namely, electric, thermal, cool and gas storage forms: battery, thermal storage electric boiler, ice storage device and P2G system. Through the reasonable configuration of energy storage devices and the optimal management of electricity discharging/charging, heating supplying/storage, cooling supplying/storage and gas production/storage, the optimal economic efficiency of RIES is achieved.

Mathematical models of different types of energy storage devices in integrated energy systems are shown in Table 1, and other major devices and their mathematical models are presented in Refs. [11-13]. 


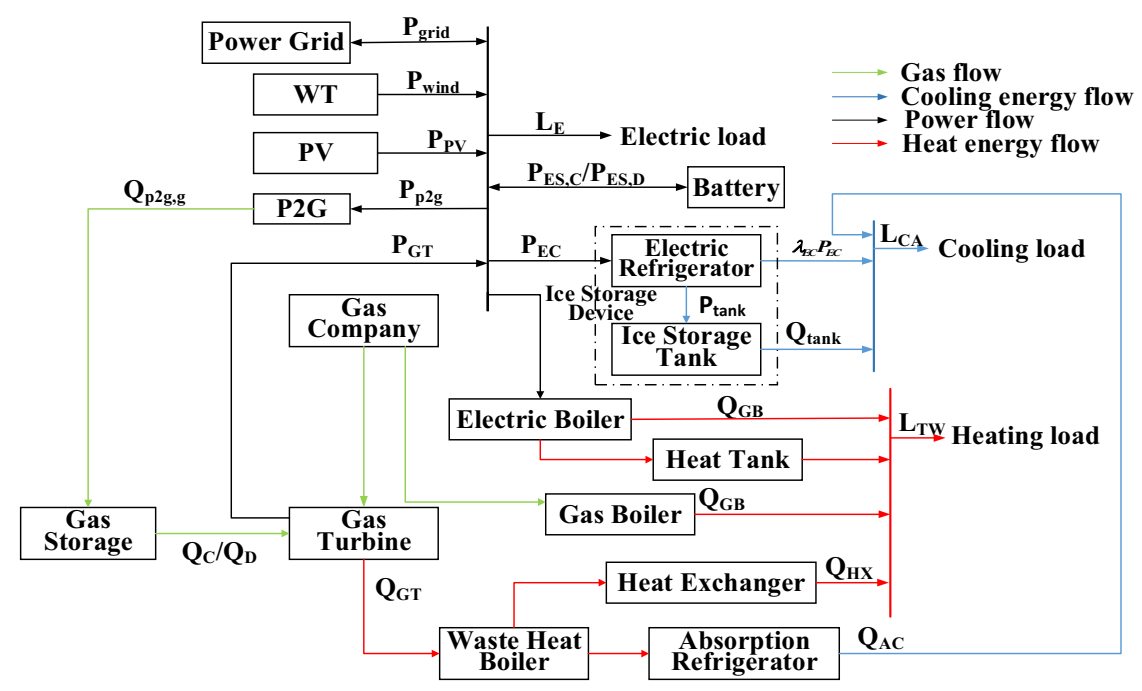

Figure 1. Schematic diagram of energy supply structure of RIES.

Table 1. Mathematical models of energy storage devices.

Device Mathematical model $\quad$ Description of main parameters

Ice storage device [12]
$P_{r e f}^{t}$ and $P_{\tan k}^{t}$ are the electrical power consumed by the refrigerator and ice storage tank at time $t ; Q_{\text {ref }}^{t}$ and $Q_{\tan k}^{t}$ are the cooling power generated by the refrigerator and the ice storage tank at time $t ; \lambda_{\text {ref }}$ is the cooling efficiency of the refrigerator; $P_{E C}^{t}$ and $Q_{E C}^{t}$ are the total electric power and cooling power of the ice storage device at time $t$; $T_{m e l t}$ indicates that the ice storage tank is in the melting period; $T_{\text {ref }}$ indicates that the ice storage tank is in the ice storage period; $E_{\tan k}^{c}$ and $\eta_{\tan k}^{c}$ are the energy efficiency ratio and ice melting efficiency of the ice storage $\operatorname{tank} ; S_{\tan k}^{t+1}$ and $S_{\tan k}^{t}$ are the ice storage capacity of the ice storage tank at time $t+1$ and time $t ; \sigma_{\tan k}^{c}$ is the self-loss coefficient of the ice storage tank.

$$
W_{E S}^{t+1}=W_{E S}^{t}\left(1-\sigma_{E S}\right)
$$

$$
+P_{E S C}^{t} \eta_{E S, C}-\frac{P_{E S D}^{t}}{\eta_{E S, D}}
$$

$W_{E S}^{t+1}$ and $W_{E S}^{t}$ are the stored energy of the battery before and after charging and discharging; $\eta_{E S, C}$ and $\eta_{E S, D}$ are the charge and discharge efficiency of the battery; $\sigma_{E S}$ is the self-discharge rate; $P_{E S C}^{t}$ and $P_{E S D}^{t}$ are the charge and discharge power of the battery, respectively. The charge and discharge status of the battery meet the mutually exclusive condition. Therefore, the battery cannot be charged and discharged at the same time. 
$P_{E B}^{t}$ is the power consumption of the electric boiler at time $t ; \lambda_{E B}$ is the efficiency of electric boiler; $h_{r, c}^{t}$ and $h_{r, d}^{t}$ are the thermal power of heat storage and heat release of the heat storage tank at time $t$, respectively; $Q_{E B}^{t}$ is the thermal power supplied by the electric boiler to the heating load at time $t ; S_{r}^{t+1}$ and $S_{r}^{t}$ are the stored heat in the heat tank at time $t+1$ and time $t ; \eta_{r, c}$ and $\eta_{r, d}$ are heat storage efficiency and heat release efficiency; $h_{r}^{\max }$ is the maximum storage and release power of the heat tank; $A_{c}^{t}$ and $A_{d}^{t}$ are the state variables, which indicate the state of heat storage and heat release, respectively. When storing heat, $A_{c}^{t}=1$ and $A_{d}^{t}=0$; when releasing heat, $A_{c}^{t}=0$ and $A_{d}^{t}=1$; $S_{r}^{0}$ and $S_{r}^{T}$ are the heat storage in the heat tank at the initial time and time $T$, respectively.
P2G system
$[15]$$\left\{\begin{array}{l}P_{p 2 g, g}^{t}=\eta_{p 2 g} P_{p 2 g}^{t} \\ W^{t+1}=W^{t}+Q_{c}^{t}-Q_{d}^{t} \\ W^{0}=W^{T}\end{array}\right.$
$P_{p 2 g}^{t}$ is the electric power consumed by the $\mathrm{P} 2 \mathrm{G}$

device at time $t ; \eta_{p 2 g}$ is the efficiency of P2G device; $P_{p 2 g, g}^{t}$ is the natural gas energy output by the P2G device at time $t ; W^{t+1}$ and $W^{t}$ are the gas storage capacity of the gas storage device at time $t+1$ and time $t ; Q_{c}^{t}$ and $Q_{d}^{t}$ are the gas storage and gas release rates of the gas storage device at time $t$. The gas storage device's gas storage and discharge status meet the mutually exclusive condition. In other words, it cannot store and discharge gas at the same time. $W^{0}$ and $W^{T}$ are the gas storage in the gas storage device at the initial time and time $T$, respectively.

\section{Optimal allocation model for multiple energy storage in regional integrated energy system}

\subsection{Quantitative indicators of system benefits}

Motivated by the implementation of energy conservation and emission reduction policies in China, low-carbon integrated energy system will become the development direction for future energy structure transformation. To this end, the impact of differ-ent types of energy storage combinations on the operation of integrated energy system is quantified in terms of economics and system carbon emission levels.

Power purchase cost:

$$
F_{\text {grid }}=\sum_{t=1}^{H} c_{e c}^{t} P_{\text {grid }}^{t} \Delta t
$$

where, $c_{e c}^{t}$ is the power purchase price at time $t ; P_{\text {grid }}^{t}$ is the electric power of the interaction between the regional integrated energy system and the large power grid at time $t ; H$ is the dispatch cycle; $\Delta t$ is the unit time period.

Gas purchase cost:

$$
F_{\text {fuel }}=\sum_{t=1}^{H} c_{f c} Q_{\text {gas }}^{t} \Delta t
$$

where, $c_{f c}$ is the unit calorific value price of natural gas; $Q_{\text {gas }}^{t}$ is the natural gas power of interaction between regional integrated energy system and gas company at time $t$.

Equipment operation and maintenance cost:

$$
F_{r m}=\sum_{m}^{n} \sum_{t=1}^{H} C_{o m, m} P_{t, m, \text { out }} \Delta t
$$

where, $C_{o m, m}$ is the operation and maintenance cost per unit output energy of equipment $m ; P_{t, m, \text { out }}$ is the output of equipment $m$ at time $t ; n$ is the total number of equipment.

Emission control cost: 


$$
F_{e m}=\sum_{k=1}^{K} \alpha_{g k} \lambda_{k} \sum_{t=1}^{H} P_{G T}^{t}
$$

where, $\alpha_{g k}$ is the external discounted cost of the $k^{\text {th }}$ type emission; $\lambda_{k}$ is the emission factor of the $k^{\text {th }}$ type emission; $K$ is the total number of emission gas types; the values of $\alpha_{g k}$ and $\lambda_{k}$ are shown in reference [16]; $P_{G T}^{t}$ is the electric power generated by gas turbine at time $t$.

System carbon emissions:

$$
E_{c}=m_{e} \sum_{t=1}^{H} P_{\text {grid }}^{t} \Delta t+m_{g} \sum_{t=1}^{H} Q_{\text {gas }}^{t} \Delta t
$$

\subsection{Optimal allocation strategies for multiple energy storage considering the quantification of low-carbon economic benefits}

The main steps of the optimal allocation strategy of multiple energy storage considering the quantification of low-carbon economic benefits include the input of initial data, the construction of system model, the determination of constraints and objective function, and the model solution. The specific flow chart is shown in Figure 2.

where, $m_{e}$ and $m_{g}$ are the $\mathrm{CO}_{2}$ unit emission intensity of the grid and natural gas, respectively.

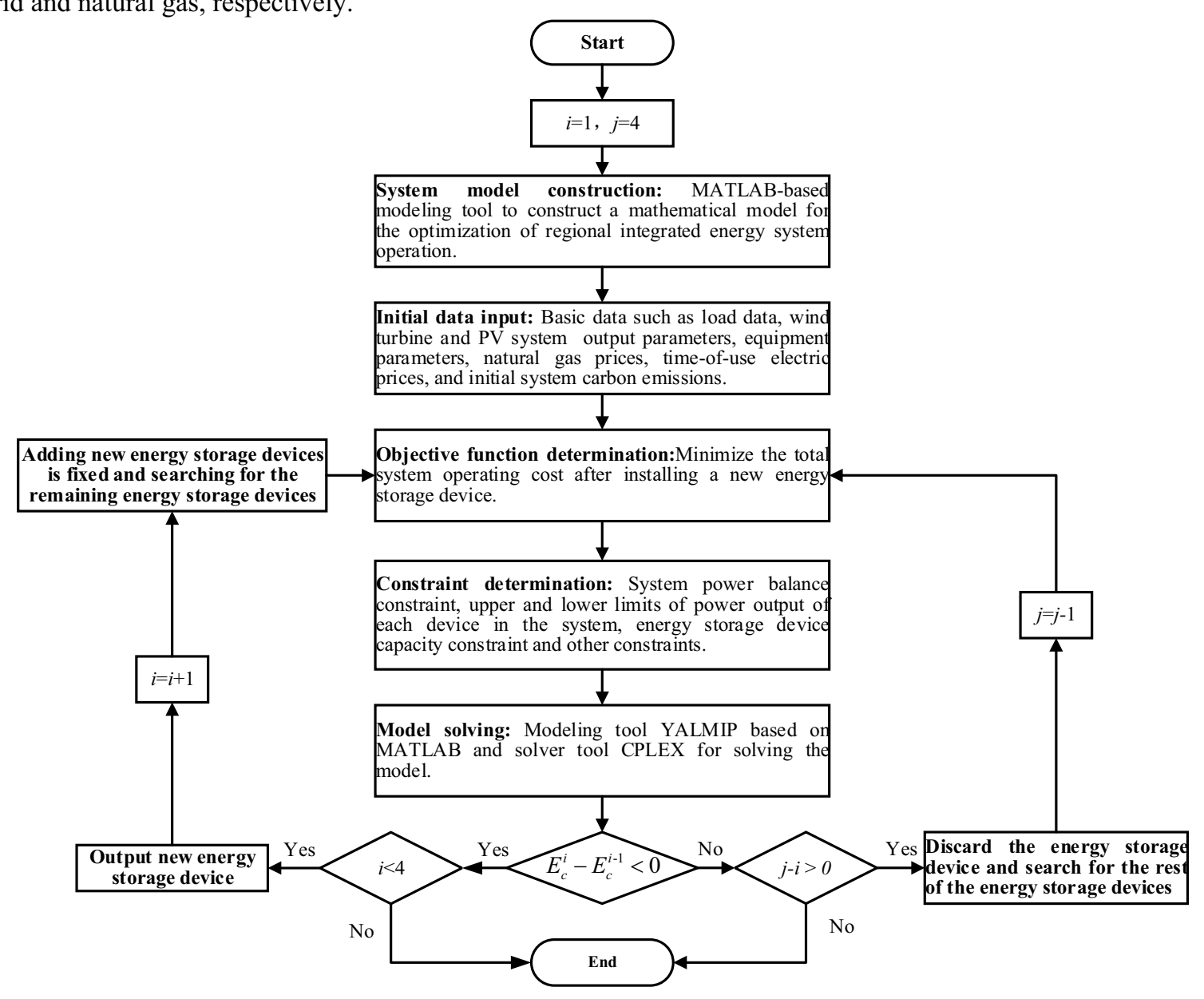

Figure 2. Flow chart of multiple energy storage optimal allocation strategy for RIES.

\subsubsection{Construction of system topological structure}

The mathematic model of the energy supply structure of regional integrated energy system as shown in Figure 1 is established in the Matlab modeling interface.

\subsubsection{Input of initial data.}

Initial data includes the cooling, heating and electric load data of the area, the power output related parameters of wind turbine and photovoltaic system, the time-sharing electricity price, natural gas price of the area and carbon emissions data for an inte-grated energy system without any energy storage, as well as the operation parameters of various equipment in the system. The operation parameters include rated conver-sion efficiency, maximum output power, rated capacity, operation and maintenance cost of each equipment.

\subsubsection{Determination of optimization objective function}

The objective function is to minimize the total operating cost of the system after adding new energy storage equipment to the system during the dispatch cycle. The components include power purchase cost, gas purchase 
cost, equipment operation and maintenance cost, and emission control cost, that is:

$$
\min C=\sum_{\Omega \cup A_{j}}\left(F_{\text {grid }}+F_{\text {fuel }}+F_{r m}+F_{e m}\right)
$$

where, $F_{\text {grid }}$ is power purchase cost of the system; $F_{\text {fuel }}$ is gas purchase cost of the system; $F_{r m}$ is equipment operation and maintenance cost of the system; $F_{e m}$ is emission control cost of the system; $\Omega \cup A_{j}$ is the collection of all devices in the system after adding a certain energy storage device.

\subsubsection{Determination of constraint conditions}

The operation constraints of regional integrated energy system include power, cooling and heating balance constraints, upper and lower limit of equipment output con-straints.

The electrical power balance constraint, cooling power balance constraint and thermal power balance constraint are defined as (7), (8) and (9), respectively:

$$
\begin{gathered}
P_{G T}^{t}+P_{P V}^{t}+P_{\text {wind }}^{t}+P_{\text {grid }}^{t}+P_{E S D}^{t}-P_{E S C}^{t}-P_{E B}^{t}-P_{p 2 g}^{t}-P_{E C}^{t}=L_{E}^{t} \\
Q_{E C}^{t}+Q_{A C}^{t}=L_{C A}^{t} \\
Q_{H X}^{t}+Q_{E B}^{t}+h_{r, d}^{t}+Q_{G B}^{t}=L_{T W}^{t}
\end{gathered}
$$

where, $L_{E}^{t}, L_{C A}^{t}$ and $L_{T W}^{t}$ are electricity, cooling and heating load power, respectively; $P_{P V}^{t}$ is the photovoltaic output power that can be absorbed by the system; $P_{\text {wind }}^{t}$ is the power output of the wind turbine that can be absorbed by the system.

\subsubsection{Solution of the model}

Considering that the previously mentioned constraints contain coupling variables, such as the charging and discharging power of the battery, 0-1 variables are introduced in the optimization model and solved using the 0-1 mixed integer linear programming approach. Meanwhile, the integrated energy system is modeled in YALMIP, a MATLAB modeling tool, and then the commercial solver CPLEX is called for the solution.

\section{Case study}

\subsection{Case parameters}

Taking a case of integrated energy system in an industrial area in northern China as the research object. The data of the case includes the power load, heating load (hot water load), cooling load and the predicted output curves of wind power and photo-voltaic units of a typical day, as shown in Figure 3.

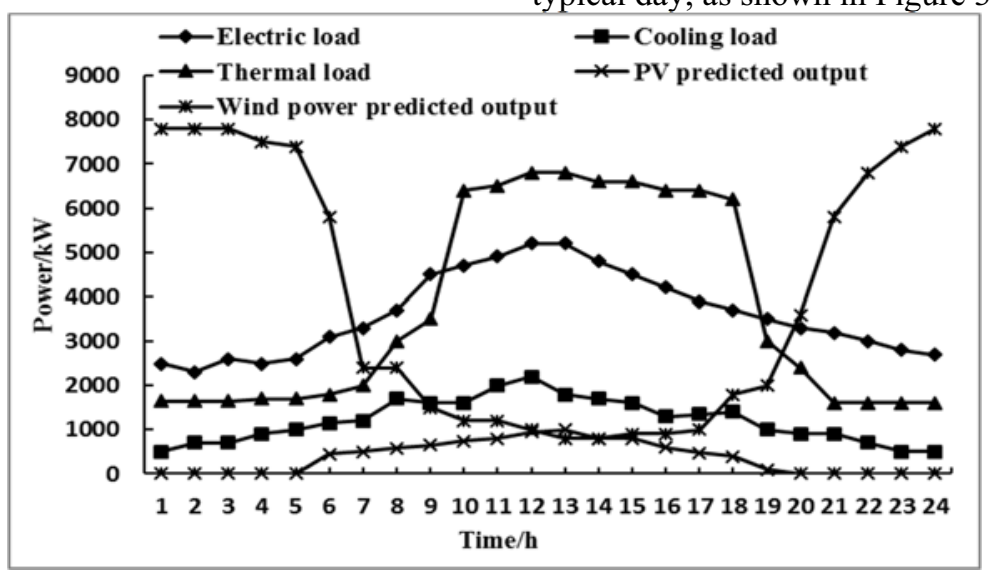

Figure 3. Electric load, thermal load, cooling load, wind power and photovoltaic output curves.

It can be seen from Figure 3 that the wind power output has the feature of reverse peak regulation. In this case, the power load at night is small, the peak of power consumption is concentrated in the daytime, and the heating load curve is also higher than the power load curve at night. When the system uses gas turbine for cogeneration heating, due to the limitation of the mode of "power by heat", the power generation capacity of gas turbine at night will increase, and because the load at night is small, the wind abandonment is more serious.

It is assumed that there is no energy storage equipment in the regional integrated energy system at the initial stage. The capacity of the energy storage equipment to be configured are determined according to the load power level. Since the average heating load per hour is about $3800 \mathrm{~kW}$, and $4000 \mathrm{~kW}$ thermal storage electric boiler is equipped, and the capacity of the heat storage device is $12000 \mathrm{kWh}$, which can meet the average heat load of 3 hours. Since the average cooling load per hour is about $1200 \mathrm{~kW}$, an ice storage tank with a capacity of $3500 \mathrm{kWh}$ is provided. The efficiency of $\mathrm{P} 2 \mathrm{G}$ equipment is about $60 \%$. P2G equipment of $4000 \mathrm{~kW}$ is equipped with a gas storage device of $12000 \mathrm{kWh}$. Due to the limitation of limited storage capacity and high cost, the configuration capacity of the battery is $3500 \mathrm{kWh}$. The price of natural gas is $0.25 \mathrm{RMB} / \mathrm{kWh}$. The main parameters of the equipment are shown in reference [17]. The data of time-sharing electricity price in this area is shown in Table 2. 
Table 2. The time-sharing electricity price.

\begin{tabular}{ccc}
\hline \multicolumn{2}{c}{ Time interval } & $\begin{array}{c}\text { Spot price/ } \\
(\mathrm{RMB} / \mathrm{kWh})\end{array}$ \\
\hline Peak periods & $\begin{array}{c}\text { 10:00-15:00 } \\
\text { 18:00-21:00 }\end{array}$ & 0.83 \\
7:00-10:00 & \\
Flat periods & $15: 00-18: 00$ & 0.49 \\
& $21: 00-23: 00$ & \\
Valley periods & $23: 00-7: 00$ & 0.17 \\
\hline
\end{tabular}

\subsection{Analysis of numerical results}

\subsubsection{Quantitative analysis of the results and benefits of sequential optimization of energy storage allocation}

The optimization result obtained by applying the optimal allocation model for multiple energy storage in the integrated regional energy system based on the optimal operating economy are shown in Table 3.

Table 3. Optimization result of energy storage configuration of RIES.

\begin{tabular}{ccccccc}
\hline $\begin{array}{c}\text { Sequence of energy } \\
\text { storage } \\
\text { configuration }\end{array}$ & $\begin{array}{c}\text { Power purchase } \\
\text { cost/RMB }\end{array}$ & $\begin{array}{c}\text { Gas purchase } \\
\text { cost/RMB }\end{array}$ & $\begin{array}{c}\text { Operation and } \\
\text { maintenance } \\
\text { cost/RMB }\end{array}$ & $\begin{array}{c}\text { Emission } \\
\text { control } \\
\text { cost/RMB }\end{array}$ & $\begin{array}{c}\text { Total } \\
\text { economic } \\
\text { cost/RMB }\end{array}$ & $\begin{array}{c}\text { System carbon } \\
\text { emissions/kg }\end{array}$ \\
\hline $\begin{array}{c}\text { Initial state } \\
\text { Thermal storage }\end{array}$ & 805.79 & 37168.4 & 3507.23 & 594.66 & 42076.08 & 74303.12 \\
electric boiler & 902.62 & 29436.65 & 3532.16 & 591.6 & 34463.03 & 60631.41 \\
Battery device & 512.9 & 28384.35 & 3449.38 & 559.31 & 32905.94 & 58107.33 \\
P2G system & 512.9 & 27071.51 & 3819.5 & 559.3 & 31963.21 & 55534.16 \\
Ice storage device & 512.9 & 26881.26 & 3783.01 & 543.97 & 31721.14 & 55161.28 \\
\hline
\end{tabular}

From Table 3, it can be concluded that the order of energy storage devices configuration in this region is thermal storage electric boiler, battery device, P2G system and ice storage device. Due to the large electric and heating loads in the region, the region will be configured with thermal storage electric boiler and battery device first. After adding the thermal storage electric boiler, the total economic cost can save 7613.05 $\mathrm{RMB}$, the saving rate can reach $18.09 \%$. The system carbon emissions are reduced by $13,671.71 \mathrm{~kg}$, which is $18.40 \%$ lower than the initial integrated energy system. Secondly, by adding the battery, the total economic cost can be further saved by $4.52 \%$ and the system carbon emission is further reduced by $4.17 \%$. The next configuration of $\mathrm{P} 2 \mathrm{G}$ system can further save $2.87 \%$ of total economic cost and further reduce $4.43 \%$ of system carbon emission. Finally, with the ice storage device, the total economic cost can be further saved by $0.76 \%$ and the system carbon emission can be further reduced by $0.67 \%$.

In terms of operational economy and system carbon emissions, a regional integrated energy system

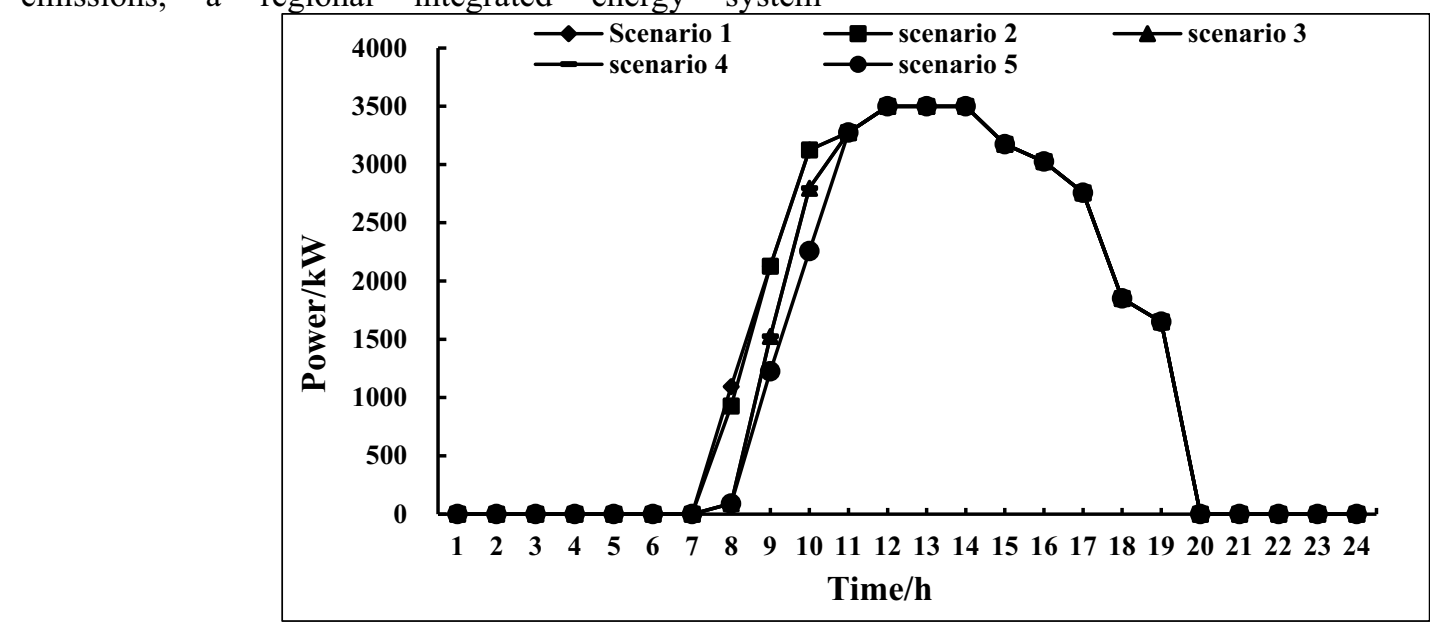

Figure 4. Output curves of gas turbines in five scenarios.

\subsubsection{Analysis of operation results}

containing four types of energy storage - electricity, gas, heating and cooling can effectively improve system energy economy, reduce system carbon emissions and relieve the pressure of regional energy carbon emissions.

In order to facilitate comparative analysis, the initial state of the integrated energy system in this area is taken as scenario 1; the integrated energy system after adding thermal storage electric boiler is taken as scenario 2; on the basis of scenario 2, the integrated energy system after adding battery device is taken as scenario 3; on the basis of scenario 3, the integrated energy system after adding $\mathrm{P} 2 \mathrm{G}$ system is taken as scenario 4; finally, on the basis of scenario 4, the integrated energy system after add-ing ice storage device is taken as scenario 5 .

The output curves of the gas turbine and gas boiler for each scenario are given in Figure 4 and Figure 5, respectively. 


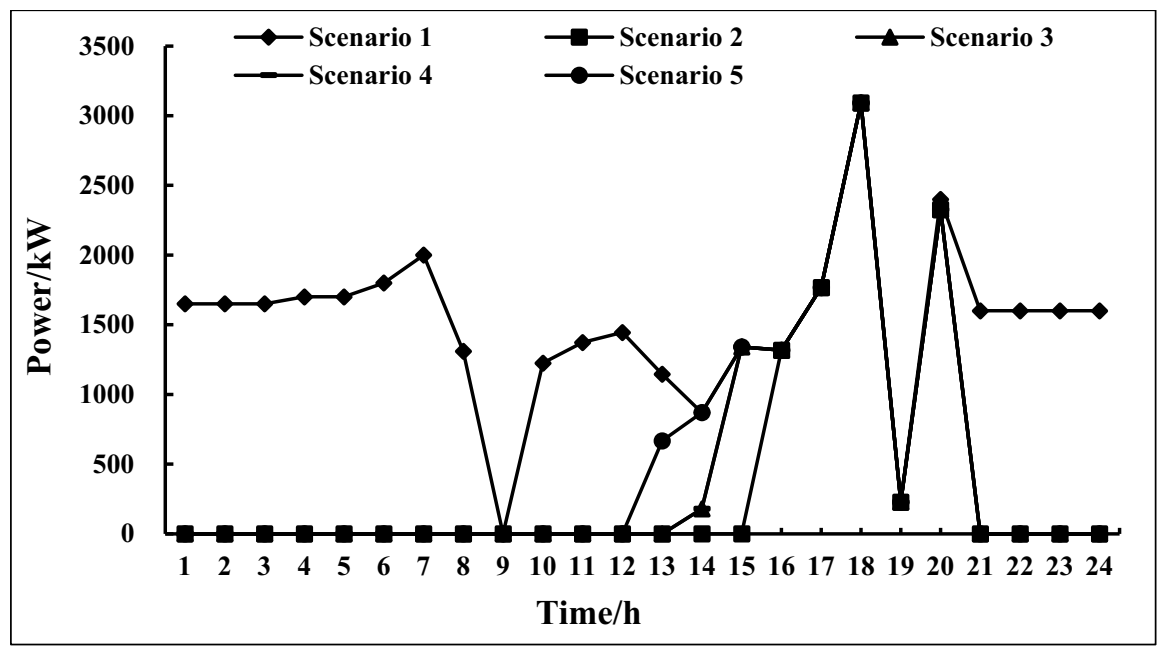

Figure 5. Output curves of gas boilers in five scenarios.

As can be seen from Figure 5, compared to scenario 1, the output of the gas boiler is significantly reduced under scenarios 2 to 5 during the periods of 00:00-13:00 and 21:00-24:00. It can be seen that the use of the thermal storage electric boiler can significantly reduce the output of the gas boiler and thus reduce the consumption of natural gas. It can be seen from Figure 4 that the output of the gas turbine is significantly reduced from 8:0011:00 in scenarios 3 to 5 compared to scenarios 1 and 2, because the battery and ice storage device store the cooling energy and electricity in advance during the low electricity price, and then reduce the output of the gas turbine by releasing the electricity and cooling energy when the electricity price increases.

Figure 6 shows the power curve of the thermal storage electric boiler in each scenario. Scenario 1 is ignored because there is no heat storage electric boiler in scenario 1. From Figure 6, it can be seen that in the periods of 00:00-08:00 and 21:00-24:00, the thermal storage electric boiler is running at full load due to the lowest electricity price.

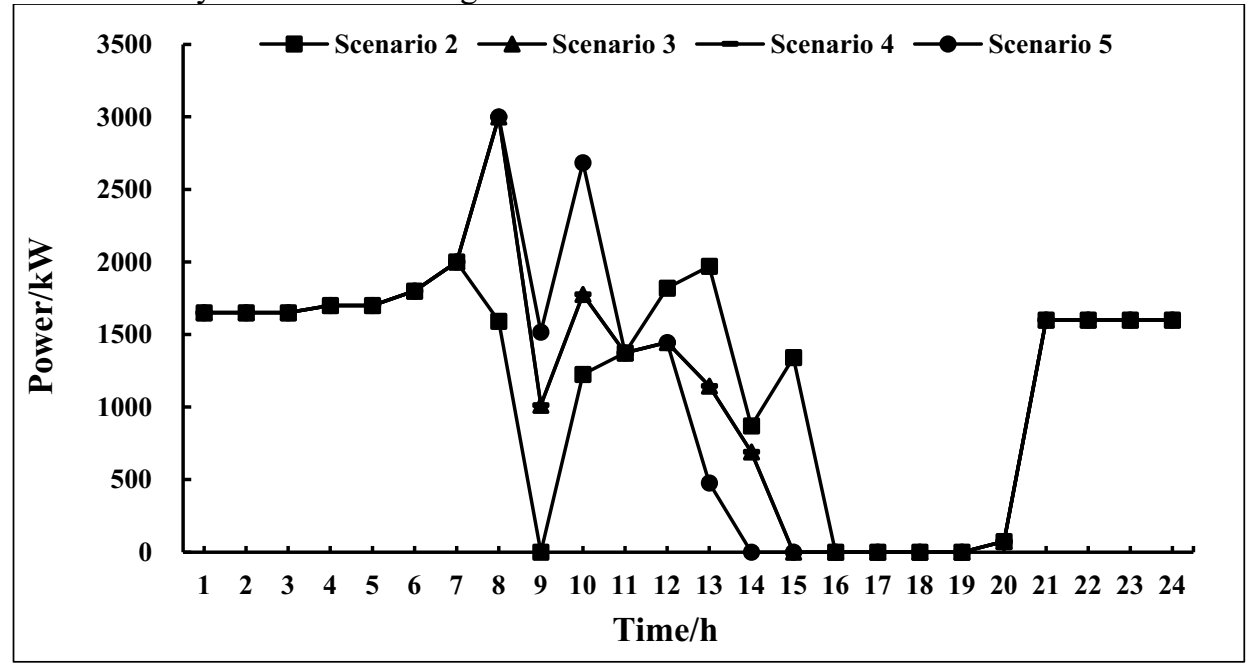

Figure 6. Output curves of thermal storage electric boilers.

The thermal energy capacity in the thermal storage tank under scenarios 2 to 5 is shown in Figure 7 . Combined with Figure 6 and 7 for analysis, the results show that the thermal storage electric boiler will regulate the operating power of the electric boiler by storing heat during low electricity price and releasing heating during high electricity price, and then coordinating with the operation of other equipment to make the comprehensive operating benefit of the system reach the maximum. 


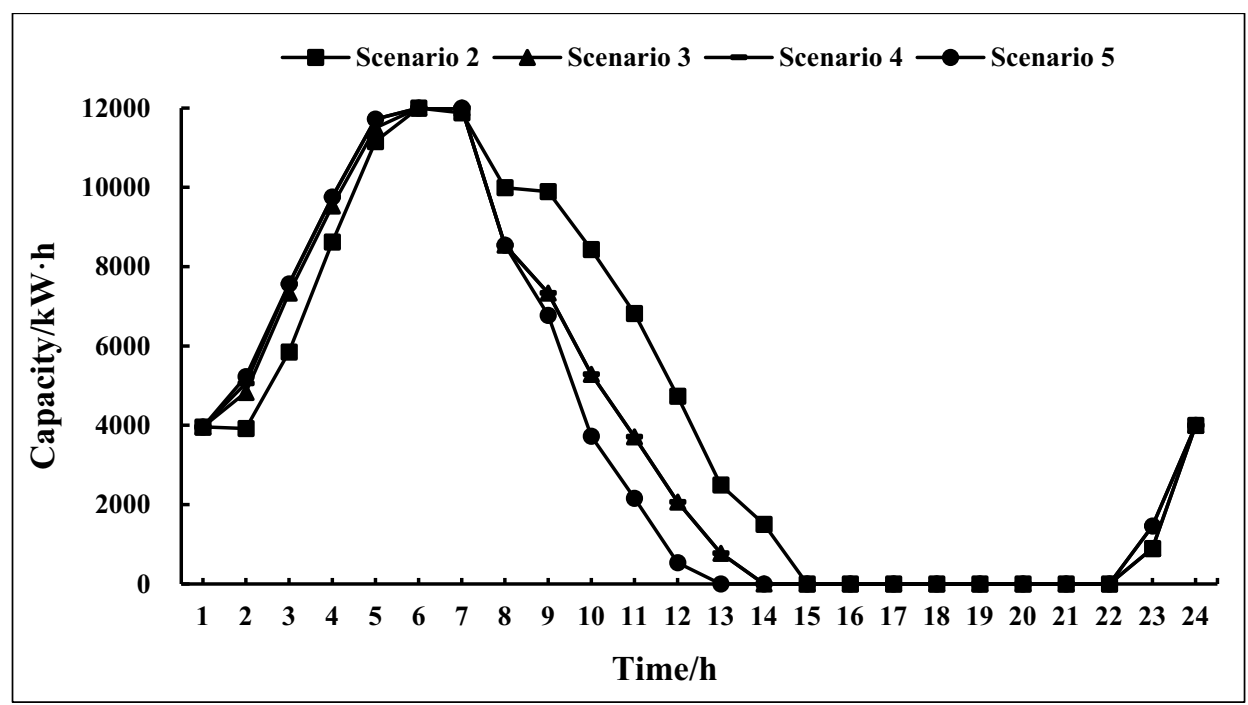

Figure 7. Hourly capacity curves of thermal energy in the thermal storage tanks under scenario 2 to scenario 5 .

Figure 8 and Figure 9 show the curves of gas and power purchased by the system from the gas company and the large grid under 5 scenarios, respectively. From Figure 8, it can be seen that in the periods of 00:00-09:00 and 20:00-24:00, the gas purchased from the gas network in scenario 1 is much higher than the other 4 scenarios. This is because at night the gas turbine output decreases, the amount of natural gas consumed decreases, and the wind power output is higher. The $\mathrm{P} 2 \mathrm{G}$ system operates with high power and converts a large amount of natural gas, so the gas purchase from the natural gas network decreases. As can be seen in Figure 9, the inclusion of energy storage devices will increase the amount of electricity purchased at low electricity prices, while at flat and peak prices, the system will reduce the amount of electricity purchased, thus providing system economics.

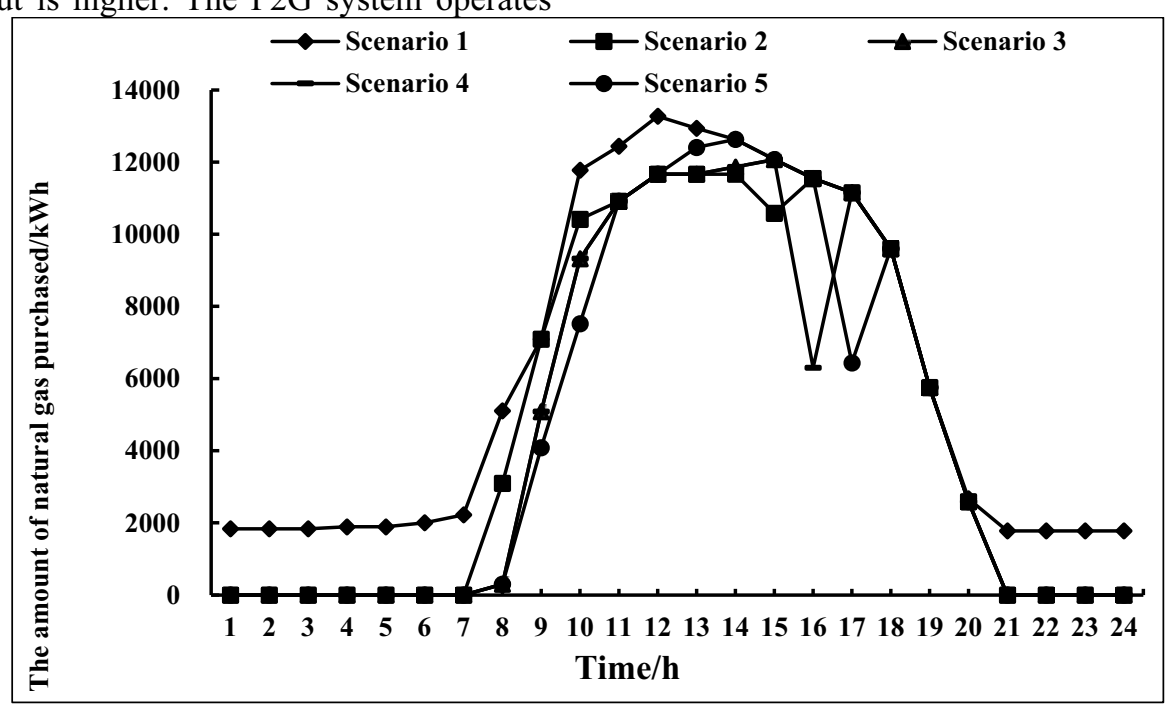

Figure 8. Purchased natural gas curves in five scenarios. 


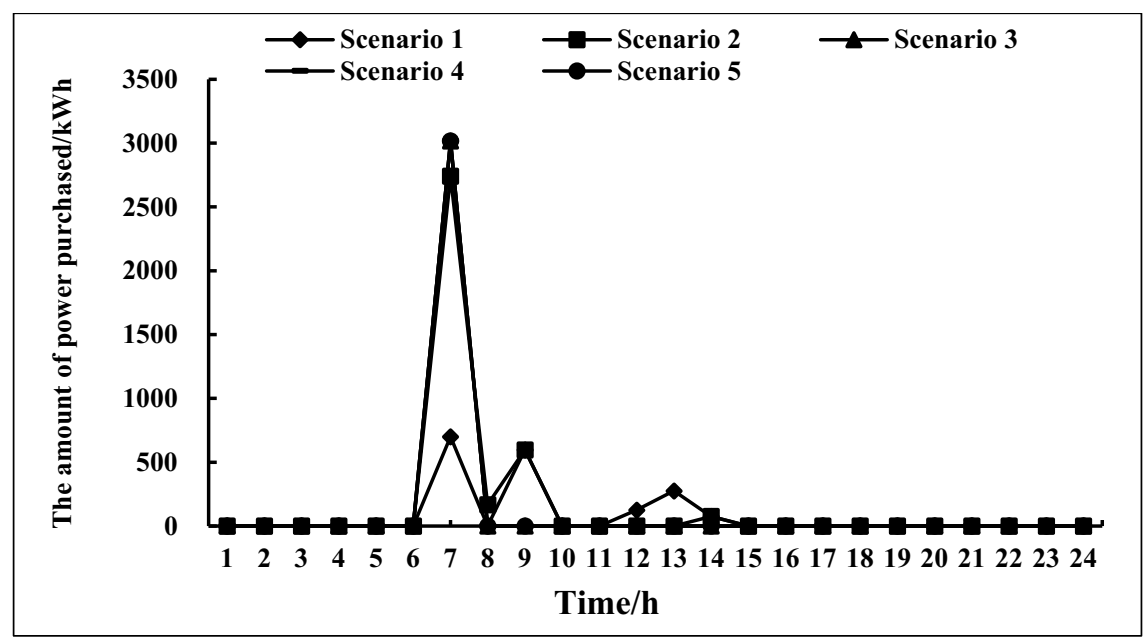

Figure 9. Purchased power curves in five scenarios.

Table 4 shows the abandoned wind power, abandoned wind rate, and abandoned power of the integrated energy system under each scenario. Under scenario 1, the system will have a large amount of abandoned wind power. After adding the thermal storage electric boiler, the wind turbine power dissipated gradually increases in each time period until scenario 4, i.e. after adding the $\mathrm{P} 2 \mathrm{G}$ system, the wind turbine power will be completely dissipated and the wind disposal rate of the system is 0 . Since the PV power is mainly concentrated in the peak load hours from 9:00 to 17:00, the PV power can be fully dissipated in all five scenarios in each time period with priority. Therefore, the energy storage devices help the integrated energy system to consume the distributed new energy.

Table 4. Results of wind power abandonment, wind abandonment rate, and solar energy abandonment under each scenario.

\begin{tabular}{cccc}
\hline Scenario & $\begin{array}{c}\text { Abandoned wind } \\
\text { power } / \mathrm{kWh}\end{array}$ & $\begin{array}{c}\text { Wind abandonment } \\
\text { rate } / \%\end{array}$ & $\begin{array}{c}\text { Abandoned solar } \\
\text { energy } / \mathrm{kWh}\end{array}$ \\
\hline 1 & 43237.50 & 46.29 & 0 \\
2 & 12972.86 & 13.89 & 0 \\
3 & 8629.46 & 9.24 & 0 \\
4 & 0 & 0 & 0 \\
5 & 0 & 0 & 0
\end{tabular}

Figure 10 shows the charging and discharging curves of each energy storage device under scenario 5. Due to the time-sharing eletric price mechanism in this paper, all the energy storage devices are in the growth state at night

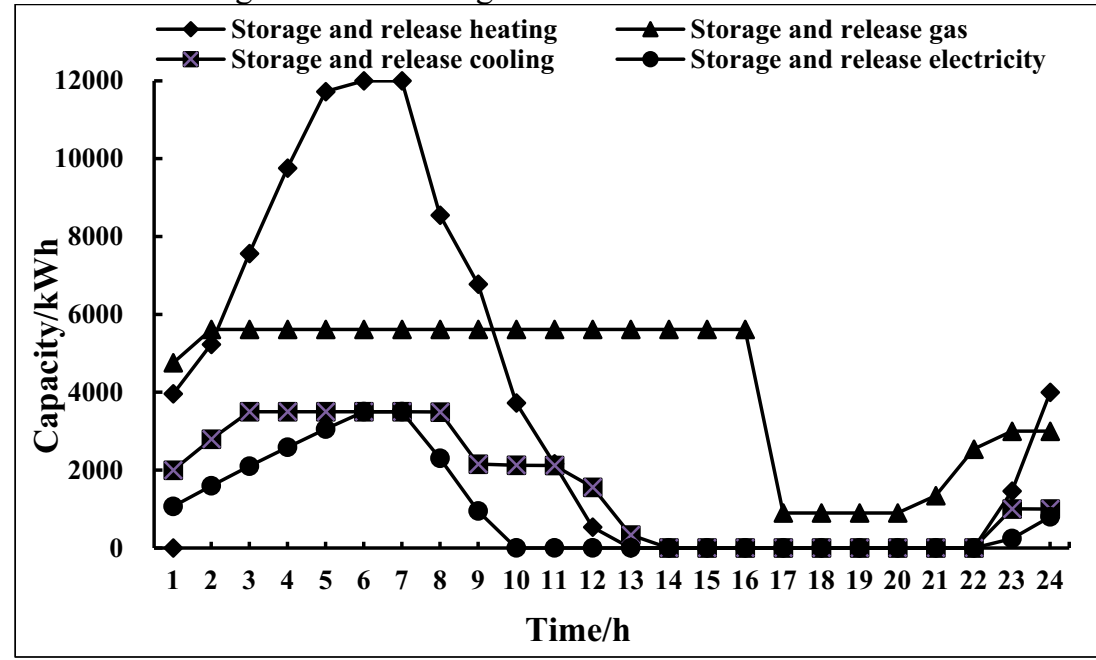

Figure 10. The charging and discharging curves of each energy storage device under Scenario 5. 


\section{Conclusion}

This paper investigated the optimal allocation method of energy storage devices in a regional integrated energy system containing multiple types of energy storage. The feasibility of the method was analyzed and verified by a case, and the following conclusions were obtained.

1) The use of an integrated energy system that includes multiple types of energy storage devices can reduce the output of gas turbine and gas boiler in the system and reduce the consumption of natural gas. Thus, it will reduce the carbon emissions of the system and respond to the national call for low carbon emission reduction policy.

2) In industrial aress where the power demands of electric and thermal loads are large and the abandoned wind amount is large, priority should be given to the config-uration of heating storage, electricity storage and gas storage. And cooling storage device is followed by them. The adoption of thermal storage electric boiler makes the heating load no longer satisfied by gas turbine alone, making the output of gas tur-bine more flexible. The use of battery device strengthens the coupling between elec-tricity and heating, and promotes the consumption of new energy from wind and light. P2G system strengthens the coupling between electricity system and natural gas system, realizing the two-way flow of energy, which is effective in improving the economic efficiency of the system and solving the problem of wind power output with anti-peak regulation.

\section{References}

1. Koirala BP, Koliou E, Friege J, et al. Energetic communities for community energy: A review of key issues and trends shaping integrated community energy systems[J]. Renewable \& Sustainable Energy Reviews, 2016, 56: 722-744.

2. Mohammadi M, Noorollahi Y, Mohammadi-Ivatloo $\mathrm{B}$, et al. Optimal management of energy hubs and smart energy hubs - A review $[\mathrm{J}]$. Renewable and Sustainable Energy Reviews, 2018, 89: 33-50.

3. GUO YJ, CHEN JM, HE HY, WU QH, HAN B, LI GJ. A review on AC/DC hybrid microgrid key technology containing distributed new energy[J]. Electric Power Construction, 2017, 38(03): 9-18. (in Chinese)

4. Monesha S, Kumar S G, Rivera M. Microgrid energy management and control: Technical review[C]// 2016 IEEE International Conference on Automatica (ICA-ACCA). IEEE, 2016.

5. XU F, MIN Y, CHEN L, et al. Combined electricityheat operation system containing large capacity thermal energy storage[J]. Proceedings of the CSEE, 2014, 34(29): 5063-5072. (in Chinese)

6. MA HR, WANG B, GAO WZ, et al. Operation optimization of energy storage equipment participating in auxiliary service in regional integrated energy system[J]. Automation of Electric Power Systems, 2019, 43(08): 34-46,68. (in Chinese)

7. LYU Q, LI L, ZHU QS, et al. Comparison of coalsaving effect and national economic indices of three feasible curtailed wind power accommodating strategies[J]. Automation of Electric Power Systems, 2015, 39(07): 75-83. (in Chinese)

8. CHENG S, HUANG TL, WAI RJ. Multi-time-scale optimal scheduling of CCHP microgrid with icestorage air-conditioning [J]. Automation of Electric Power Systems, 2019, 43(05): 30-40. (in Chinese)

9. LIU JC, ZHOU CY, GAO H, et al. A day-ahead economic dispatch optimization model of integrated electricity-natural gas system considering hydrogengas energy storage system in microgrid[J]. Power System Technology, 2018, 42(01): 170-179. (in Chinese)

10. MEN XY, CAO J, WANG ZS, et al. The Constructing of Multi-energy Complementary System of Energy Internet Microgrid and Energy Storage Model Analysis[J]. Proceedings of the CSEE, 2018, 38(19): 5727-5737,5929. (in Chinese)

11. Fumo N, Mago PJ, Chamra LM. Emission operational strategy for combined cooling, heating, and power systems[J]. Applied Energy, 2009, 86(11): 2344-2350.

12. Bao Z, Zhou Q, Yang Z, et al. A multi time-scale and multi energy-type coordinated microgrid scheduling solution-Part I: model and methodology[J]. IEEE Transactions on Power Systems, 2015, 30(5): 2257-2266.

13. Sahibzada MA, Zahid U, Geev M, et al. Smart grid and energy district mutual interactions with demand response programs, IET Energy Systems Integration, 2019, 2(1): 1-8.

14. Yang XY, Ye TZ, Zhang Y. A novel optimization model for combined wind power accommodation and electric boiler with thermal storage[J]. International Journal of Energy Research, 2019, 43(12).

15. Clegg S, Mancarella P. Integrated modeling and assessment of the operational impact of Power-toGas (P2G) on electrical and gas transmission networks[J]. IEEE Transactions on Sustainable Energy, 2015, 6(4): 1234-1244.

16. Pipattanasomporn M, Willingham M, Rahman S. Implications of on-site distributed generation for commercial/industrial facilities. IEEE Transactions on Power Systems, 2005, 20(1): 206-212.

17. SHI QS, DING JY, LIU K, et al. Economic optimal operation of microgrid integrated energy system with electricity,gas and heat storage[J]. Electric Power Automation Equipment, 2019, 39(08): 269276,293. (in Chinese) 